\title{
Digital collaborative learning: identifying what students
}

\section{value [version 1; peer review: 2 approved]}

\section{Claire Hemingway ${ }^{1}$, Catrina Adams², Molly Stuhlsatz ${ }^{3}$}

${ }^{1}$ National Science Foundation, Arlington, Virginia, 22204, USA

${ }^{2}$ Botanical Society of America, St. Louis, Missouri, 63166, USA

${ }^{3}$ Biological Science Curriculum Study, Colorado Springs, Colorado, 80918, USA

V1 First published: 20 Mar 2015, 4:74

https://doi.org/10.12688/f1000research.6223.1

Latest published: 20 Mar 2015, 4:74

https://doi.org/10.12688/f1000research.6223.1

\section{Abstract}

Digital technologies are changing the learning landscape and connecting classrooms to learning environments beyond the school walls. Online collaborations among students, teachers, and scientists are new opportunities for authentic science experiences. Here we present findings generated on PlantingScience (

www.plantingscience.org), an online community where scientists from more than 14 scientific societies have mentored over 14,000 secondary school students as they design and think through their own team investigations on plant biology. The core intervention is online discourse between student teams and scientist mentors to enhance classroom-based plant investigations. We asked: (1) what attitudes about engaging in authentic science do students reveal, and (2) how do student attitudes relate to design principles of the program? Lexical analysis of open-ended survey questions revealed that students most highly value working with plants and scientists. By examining student responses to this cognitive apprenticeship model, we provide new perspectives on the importance of the personal relationships students form with scientists and plants when working as members of a research community. These perspectives have implications for plant science instruction and e-mentoring programs.

Keywords

Attitudes, Plant Science, E-mentoring, Authentic Science, StudentTeacher-Scientist Partnership

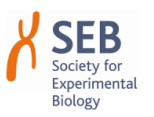

This article is included in the Teaching and communicating science in a digital age collection.
Open Peer Review

\begin{tabular}{lcc} 
Approval Status & 1 \\
\hline & 1 & 2 \\
\hline version 1 & \\
\hline 20 Mar 2015 & view & view
\end{tabular}

1. Melanie Link-Perez, Armstrong State

University, Savannah, USA

2. Graham Scott, University of Hull, Hull, UK

Any reports and responses or comments on the article can be found at the end of the article. 
Corresponding author: Claire Hemingway (chemingw@nsf.gov)

Competing interests: Catrina Adams currently leads the PlantingScience program; Claire Hemingway led the program until 2013.

Grant information: Funding from the National Science Foundation (NSF DRL 0733280) supported in part the program activities of PlantingScience from 2007 to 2012. Contents of this publication are solely the responsibility of the authors and do not necessarily represent official views of the NSF. No grants were involved in supporting the study presented here.

The funders had no role in study design, data collection and analysis, decision to publish, or preparation of the manuscript.

Copyright: (c) 2015 Hemingway C et al. This is an open access article distributed under the terms of the Creative Commons Attribution License, which permits unrestricted use, distribution, and reproduction in any medium, provided the original work is properly cited. Data associated with the article are available under the terms of the Creative Commons Zero "No rights reserved" data waiver (CC0 1.0 Public domain dedication).

How to cite this article: Hemingway C, Adams $\mathrm{C}$ and Stuhlsatz M. Digital collaborative learning: identifying what students value [version 1; peer review: 2 approved] F1000Research 2015, 4:74 https://doi.org/10.12688/f1000research.6223.1

First published: 20 Mar 2015, 4:74 https://doi.org/10.12688/f1000research.6223.1 


\section{Introduction}

A revolution in digital learning is underway. The number of students taking online courses in the United States has skyrocketed to 7.1 million in higher education institutions (Allen \& Seaman, 2014) and almost 750,000 in public primary and secondary schools (Evergreen Research Group, 2014). Digital technologies offer new mechanisms to support reform-based approaches and increase student engagement. Transforming traditional college and pre-college classrooms into active-learning environments where students interact with peers and instructors to collectively construct and apply knowledge can positively impact student attitudes towards science (Armbruster et al., 2009; Gibson \& Chase, 2002; Taraban et al., 2007; Ward et al., 2014). A significant challenge to the tremendous potential for the digital learning revolution is transferring authentic science investigations to digital learning environments. There is a particular need to investigate students' attitudes about technologyenhanced science investigations in precollege settings, as this is a critical time when interest in science can set the direction of future career goals (Maltese \& Tai, 2011).

How students and teachers experience plant science is a focus of concern; alarming trends in U.S. formal education show that plants are under-represented in teaching materials, and poorly understood. A decline in botanical literacy is part of the continuing U.S. crisis in science literacy, although some underlying causes are unique to botany. The best-selling U.S. high school biology texts feature primarily animals (Uno, 1994). Teachers also place a focus on animals; when choosing material to teach biological concepts, teachers reported preferring to use animal examples over plant examples (Flannery, 1999; Link-Perez \& Schussler, 2013). Pre-service teachers (Krantz \& Barrow, 2006) and young learners (Barman et al., 2006) hold many of the same misconceptions (or alternate conceptions) about plants. High school biology teachers from across the U.S. report being least confident about plant biology when surveyed about five fundamental topics, and just $46 \%$ of those with 6 years or less teaching experience report having ever had a botany course (Horizon Research Inc., 2002; Horizon Research Inc., 2013). The problem is not restricted to the U.S. Research on the uptake of plant sciences in the United Kingdom shows that the majority of UK students entering university biology courses have little interest in or knowledge of plants (Stagg et al., 2009).

Compounding these documented issues is the human tendency to overlook plants, known as 'plant blindness' (Wandersee \& Schussler, 1999), which has both cultural and physiological underpinnings (Balas \& Momsen, 2014). Educators, students, and the public who generally don't notice plants in the environment are not likely to see that plants are of utmost importance to the food, fuel, fibers and pharmacology of everyday life, as well as the functioning of our global ecosystem. A future workforce prepared with an understanding of plant science and cross-cutting concepts applied in innovative solutions will be needed to meet societal challenges, such as coping with climate change, feeding an increasing population, and generating sustainable energy sources (National Research Council, 2009). Engaging scientists as mentors has the potential to inspire interest and to link classroom learning to real-world authentic science. For plant science, meaningful and early exposure may be critical:
"The presence of a plant mentor earlier in one's life (someone who helped the mentee observe, plant, grow, and tend living plants) is a key predictor of that person's awareness, appreciation, and understanding of plants throughout the lifespan." (Wandersee \& Clary, 2006).

Given the need to enhance teaching and learning about plants in formal U.S. education and the promise of student-scientist partnerships (Houseal et al., 2014; Summers \& Hrabowski, 2006), we have been engaged in an approach to foster student learning of scientific practices and plant biology through interactions with scientist mentors. The PlantingScience program was intentionally developed as a blended approach to student-centered experiential learning taking place in the classroom, supplemented by communication and collaboration with peers and experts online. The online platform (www.plantingscience.org) not only eliminates geographic limitations, its design features make student thinking visible, enabling students, teachers and mentors to monitor thinking and learning and provide feedback. An impetus for this study was to take a systems approach to examining the inputs and outputs of PlantingScience. A previous study examined the techniques mentors used in online discourse with student teams (Adams \& Hemingway, 2014). Here we examine the attitudes (affective responses) of students participating in collaborative plant investigations. We present qualitative data on what students value about a digital learning environment in which science practices and content are integrated and science experts and novices collaborate, as it occurs in authentic science research. We ask what major themes emerge from the student responses and how the exploratory analyses relate to design features of the program.

\section{Methods}

\section{Context of PlantingScience}

Students ages 11 to 18 are the focus of this study. The students mentored by volunteer scientists enter the program through their teachers, who typically are seeking inquiry learning opportunities for their students. Participating classrooms (60\% high school, $40 \%$ middle school) come from a variety of demographics; rural, urban, public and private schools. Classroom teachers choose one of the eight available investigation themes and decide whether the 3-12 week long projects would be limited to controlled experimentation or include observational studies; their past experience with inquiry often determines how guided or open student projects will be. The research questions and plants used by student teams vary widely; however, all investigations intend for students to collaboratively develop a research question on a core idea in plant biology, plan and carry out an investigation to answer the question, analyze the data, and make sense of the findings.

Each student team is assigned a unique project page where they are encouraged to post information about their research project, as well as engage in asynchronous dialog with the mentor matched to their team. The program's 988 registered mentors, from undergraduate students to professor emeriti, belong to more than 14 scientific societies that partner in the program. Student pre- and post-tests are not mandatory, and they are administered through the online platform, which is a customization of the open-source content management system Zikula. The Institutional Review Board of Texas A\&M University granted approval for collection of these data, and we obtained 
permission from schools, students, and parents where appropriate, for publication. Over 4000 team projects with associated dialog, archived since 2005 are available at www.plantingscience.org.

\section{Data sources}

For this study we analyzed students' open-ended responses to the post-test survey question, "What did you like most about this experience?" Following six online mentored inquiry sessions between 2010 and 2012, only $2.7 \%$ of the students who initiated the online survey did not complete the open-ended question. A total of 2,617 responses from middle school $(n=947)$ and high school $(n=1,670)$ students were analyzed. The students completing surveys over this period were in classrooms of 20 middle school and 42 high school teachers. These classrooms encompassed a range of private and public schools, including two international classrooms. As expected given that "Wonder of Seeds" is the most frequently used module, more than half $(54.6 \%)$ of the students who completed the surveys had conducted germination and/or seedling growth studies.

\section{Dataset 1. Student Responses}

http://dx.doi.org/10.5256/f1000research.6223.d44181

Anonymized, raw data of student responses to optional open-ended survey question administered online following secondary school students' participation in the online mentored inquiry experience.

\section{Analysis of student attitudes}

We downloaded the student responses from the archives in the online platform, removed errant duplications, and then imported an aggregated file into IBM $^{\circledR}$ SPSS $^{\circledR}$ Text Analytics for Surveys version 4 (IBM copyright 2010). As responses to the open-ended survey question typically ranged from one to several sentences, the computational linguistics text mining tool simplified the creation of broad sets of categories across responses. From the initial automated categorization of results, we discussed refinement to the categories through several iterations. In particular, we identified where automated codes were not applied appropriately, automated categories were conceptually related, and custom terms needed. For example, student comments about observations, collection of data, measurement, and analysis of data were manually grouped in an overarching category on the practice and processes of science. Similarly, text referring to seeds and germination were grouped, and the students' various descriptions of doing experiments, labs, or projects were defined as synonyms. This iterative, exploratory process results in a robust view of the elements of most interest to the students as well as allowing one to investigate connections between areas of interest.

\section{Results}

To put the student survey data in perspective, we first present statistics on content of the project pages as a way to quantify the student experience and to provide some context of what the experience involved during the period investigated here (Table 1). Most student projects included information on the team's research question, prediction, experimental design and conclusion. Projects variably included supplemental documentation about their team research. The number of asynchronous posts between student teams and mentors ranged widely. There are many factors that account for the wide
Table 1. Summary of types of content posted on the student teams' online project pages.

\begin{tabular}{|l|l|}
\hline $\begin{array}{l}\text { Type of content posted } \\
\text { Team Research Information and } \\
\text { Supporting Documentation }\end{array}$ & $\begin{array}{l}\text { Posting Statistic } \\
\text { posting content }\end{array}$ \\
\hline Research question & $95 \%$ \\
\hline Prediction & $91 \%$ \\
\hline Experimental design & $85 \%$ \\
\hline Conclusion & $61 \%$ \\
\hline Team photo & $89 \%$ \\
\hline Other images & $51 \%$ \\
\hline Research journal files & $44 \%$ \\
\hline Data files & $39 \%$ \\
\hline Final presentation files & $25 \%$ \\
\hline Comments between teams and mentor & Average and range \\
\hline Mentor posts to student teams & $6.5(1-43)$ \\
\hline Student posts (all team members) to mentor & $12.5(1-124)$ \\
\hline
\end{tabular}

range in student post numbers, from teachers' directions whether all students should post or appoint a team spokesperson, to the number of days computers are available, to teachers' grading structures, to individual student motivation levels.

Across all survey results, students mentioned most frequently four themes as favored elements: plants $(26.9 \%)$, scientist-mentor (20.3\%), growing (15.7\%), and experiments (13.8\%). While some students responded to the open-ended question by noting only one thing that they liked most, other comments mentioned multiple elements in the same sentence(s). Relationships between themes mentioned by students illustrate a complex network of the four major nodes and how they are interconnected and also cross-linked to other favored elements (Figure 1). We next narrowed the selection for a view of the networks associated with each of the four major nodes in turn.

What many students explicitly liked about plants was growing them, although the comments about liking plants formed a relatively dense web of connections to other items (Figure 2). Looking closely at the language that students use about plants, we saw two subtle, distinct descriptions about interactions with their study organisms. Students expressed a sense of enjoyment as a result of their interaction with plants, which was often connected to closely observing their plants: "I enjoyed seeing my plants grow and display their traits." Less commonly but importantly students expressed a personal relationship, often a personal responsibility, for tending to their plants. (1) "Working with and caring for the plants was my favorite part." (2) "The caring and effort you had to put into it. It was kind of like babysitting a child you could say. Because just like a child you had to watch and care for it." Students mentioned liking the plants together with a wide array of other aspects of the PlantingScience experience such as the procedural aspects of manipulating variables and the social aspects of working with friends, classmates, and scientists. Taken together student comments about liking "plants" and "growing" account for the majority of favored program elements. 


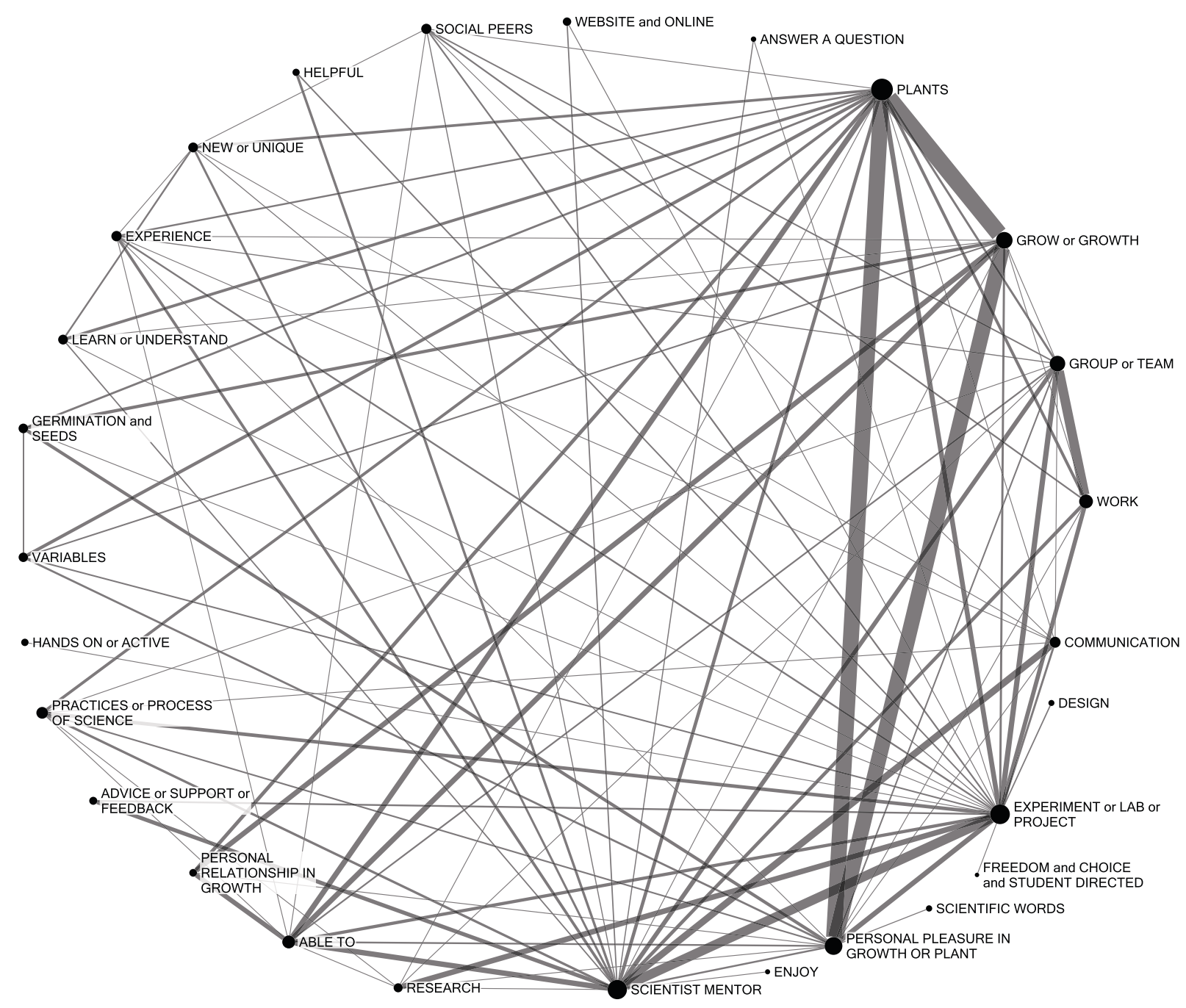

Created with NodeXL (http://nodexl.codeplex.com)

Figure 1. Lexical web illustrating the four themes that students liked most and connections among favored elements. The size of the node represents the number of total respondents liking that element, and the width of the line between nodes is weighted by the number of shared responses. Items with fewer than 20 respondents are filtered out to simplify the lexical web. The size of the nodes corresponds to the number of responses in a given category, while the thickness of the lines represents the number of links between categories.

The network of comments that students made about liking most their mentor shows strong connections to many aspects of doing and learning science as part of a science community (Figure 3). When commenting about liking their mentor, students also noted the uniqueness and the global viewpoint of the online experience. For example, comments included references to experiments, answering a question, communication, advice, team, help, and advantages. Three student quotes that illustrate several of these connections in context are: (1) "It was great working with a scientist who took the time to give us meaningful feedback. It really helped me learn and experiment." (2) "The ability to interact with real life scientists was interesting and unprecedented in my life. Our group bonded with our mentor and it provided an awesome experience overall, as well as the chance to create and enact our own experimental design." (3) "I liked having the advantage to speak with scientists from other areas around the world and looking at other experiments being done by other students. This to me helped give my group and I more ideas for our experiment and it kind of showed us how we could improve ours and make it a little more detailed with less problems."

Although students less commonly cited liking most the experience of engaging in scientific practices and experiments, comments on this fourth major theme were also connected to the mentor, the collaborative team research, and the liberation that student-led inquiry offers (Figure 4). Phrases such as "we got to" or "I was able to" or "had the freedom to" were common signs that students valued the ownership of their research project and ideas. Students appreciated getting to choose variables, particular techniques, particular species of plants as subjects, and the research question. Students also valued the combination of independence and collaboration of the environment in terms of working with and learning from others. Two student quotes capture both of these themes: (1) "It was 


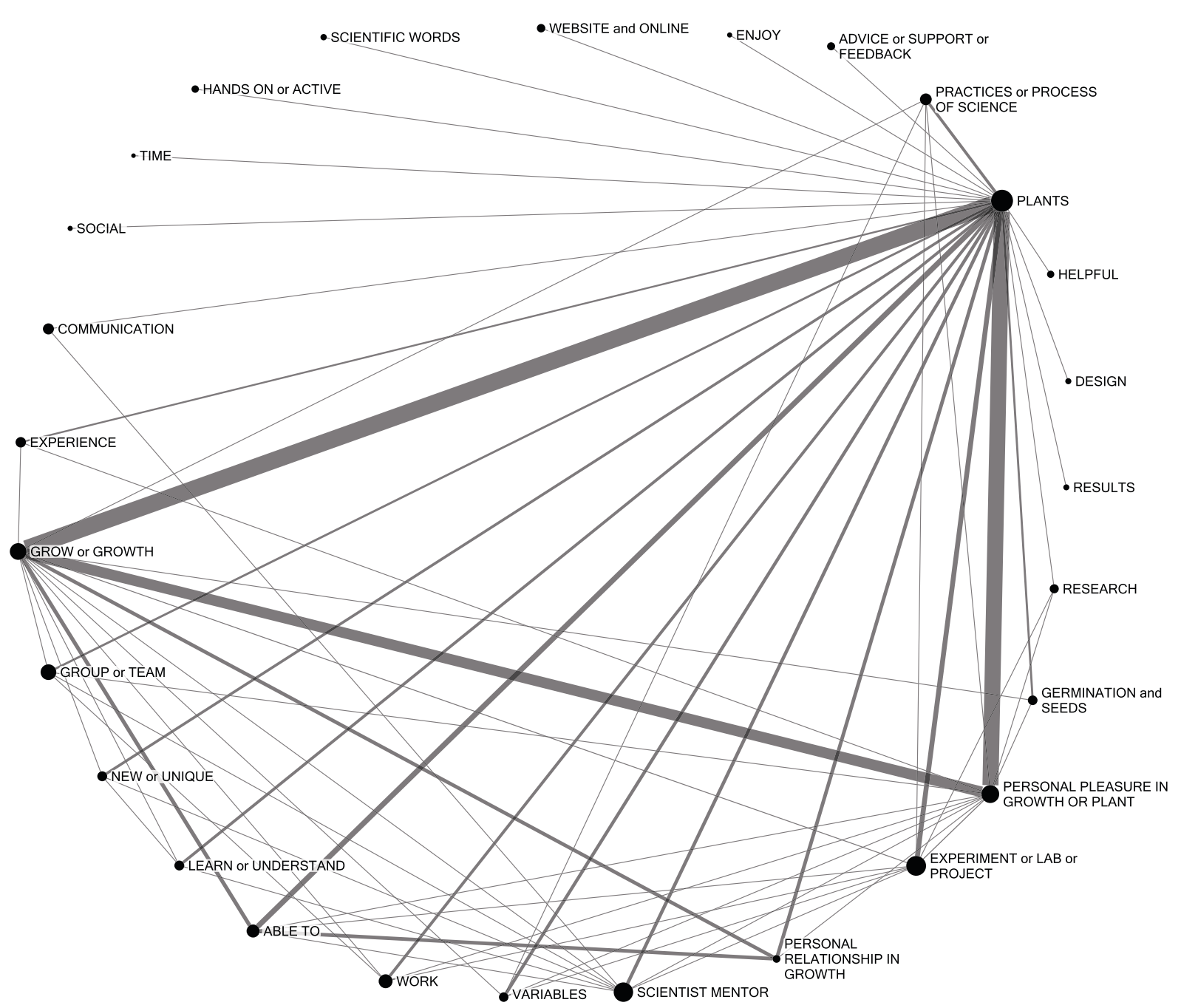

Created with NodeXL (http://nodexl.codeplex.com)

Figure 2. Lexical web illustrating connections of students' comments about liking the plants to other favored elements. The size of the node represents the number of total respondents liking that element, and the width of the line between nodes is weighted by the number of shared responses. Items with fewer than 10 respondents are filtered out to simplify the lexical web.

interesting to see what kinds of experiments different people came up with, and how they went about testing their hypothesis. I also like coming up with our idea in itself," (2) "I liked how personal it was with our mentor, I also really enjoyed the freedom we had on deciding what we wanted to do and how we wanted to do it. We just picked our project then we tested everything ourselves and planned out everything and presented it just like real scientists would."

\section{Discussion}

The aggregated responses provide a picture of the major features that students appreciate most from the blended learning experience of conducting team-led plant investigations in their classrooms and collaborating with domain experts and peers online. Students highly value communicating with their mentors; it both creates a personal connection and provides students with a contextualized experience, working as part of a scientific community. Student comments about scientific practices demonstrated the importance they place on ownership of their own learning and the value of integrating authentic practices like data collection and interpretation into the experience. This study also indicates that students highly value, perhaps most of all, the interactions they have with plants as their study organisms.

As an examination of student attitudes toward program design features, this analysis suggests that key objectives are being met and it hints to some challenges for digital learning environments. Many students responded favorably to the design features that promote experiential and collaborative learning with plants, connections to scientists, and digital opportunities for feedback and reflection. A previous study documented that participating scientists use an array of mentoring techniques including socializing students into science, modeling scientific thinking, and combining content and practices naturally (Adams \& Hemingway, 2014). Here we see that participating students respond by expressing appreciation for the personal 


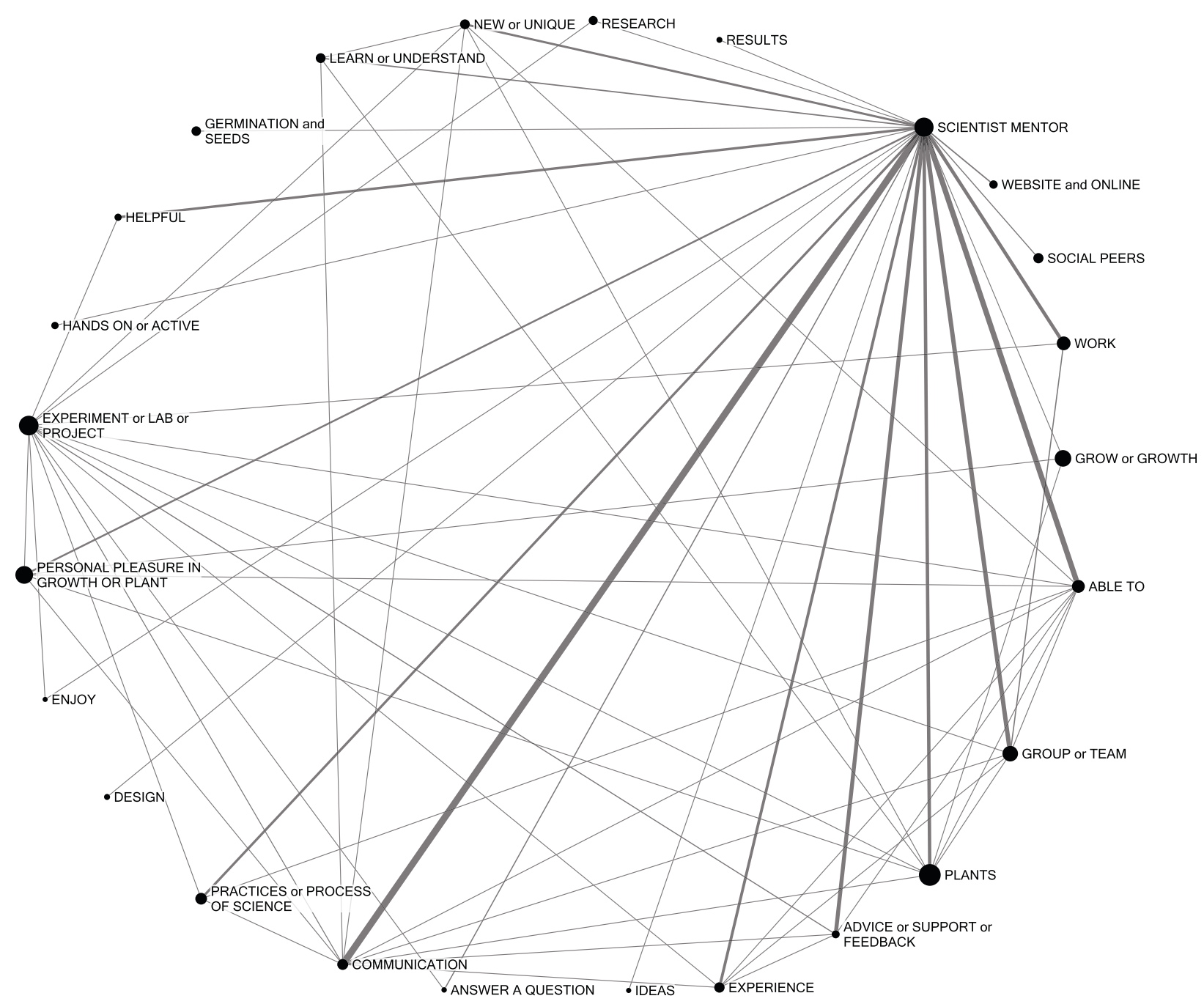

Created with NodeXL (http://nodexl.codeplex.com)

Figure 3. Lexical web illustrating connections of students' comments about liking their mentors to other favored elements. The size of the node represents the number of total respondents liking that element, and the width of the line between nodes is weighted by the number of shared responses. Items with fewer than 20 respondents are filtered out to simplify the lexical web.

relationships they form with scientists, plants, and peers while working as members of a research community. As digital connection to domain experts was a key program intervention, the stronger student response to plants than mentors warrants discussion and further exploration. Students interacted daily with plants and intermittently with their mentors during the course of the team investigations. Challenges of asynchronous discourse with mentors that likely play a role include communication delays, computer access and school schedules and the classroom being a "black box" to some scientists. The frequency of exposure may also influence the high frequency with which students cited liking plants. We would argue the students' strong positive attitude towards plants as their study subjects reflects an authentic trajectory for developing scientists. Mentors may open the door to the scientific enterprise, and once through it is the discovery process that captures students' intellectual curiosity. Mentors, advisors, sponsors-more senior experts by any name and at any stage of the career path-are facilitators or cultivators, not generators, of individual wonder and talent.

Prior studies have shown that students studied in several countries find plants less interesting than animals, uninteresting, or downright boring (Fancovicova \& Prokop, 2010; Kinchin, 1999; Randler et al., 2012). While our study was not designed to test students' relative interest in plants versus animals, our findings of students' strongly positive attitude about working with plants in this learning setting indicates that how students are exposed to plants matters a great deal. This view is not new (Uno, 2009), and it is reinforced by other studies. For example, learning experiences that emphasized observations in the local environment enhanced interest in both plants and animals among Swiss precollege students (Lindemann-Mathhies, 2005). Similarly, improvements in student attitudes towards plants accompany shifts in curricular approach to student-centered, active 


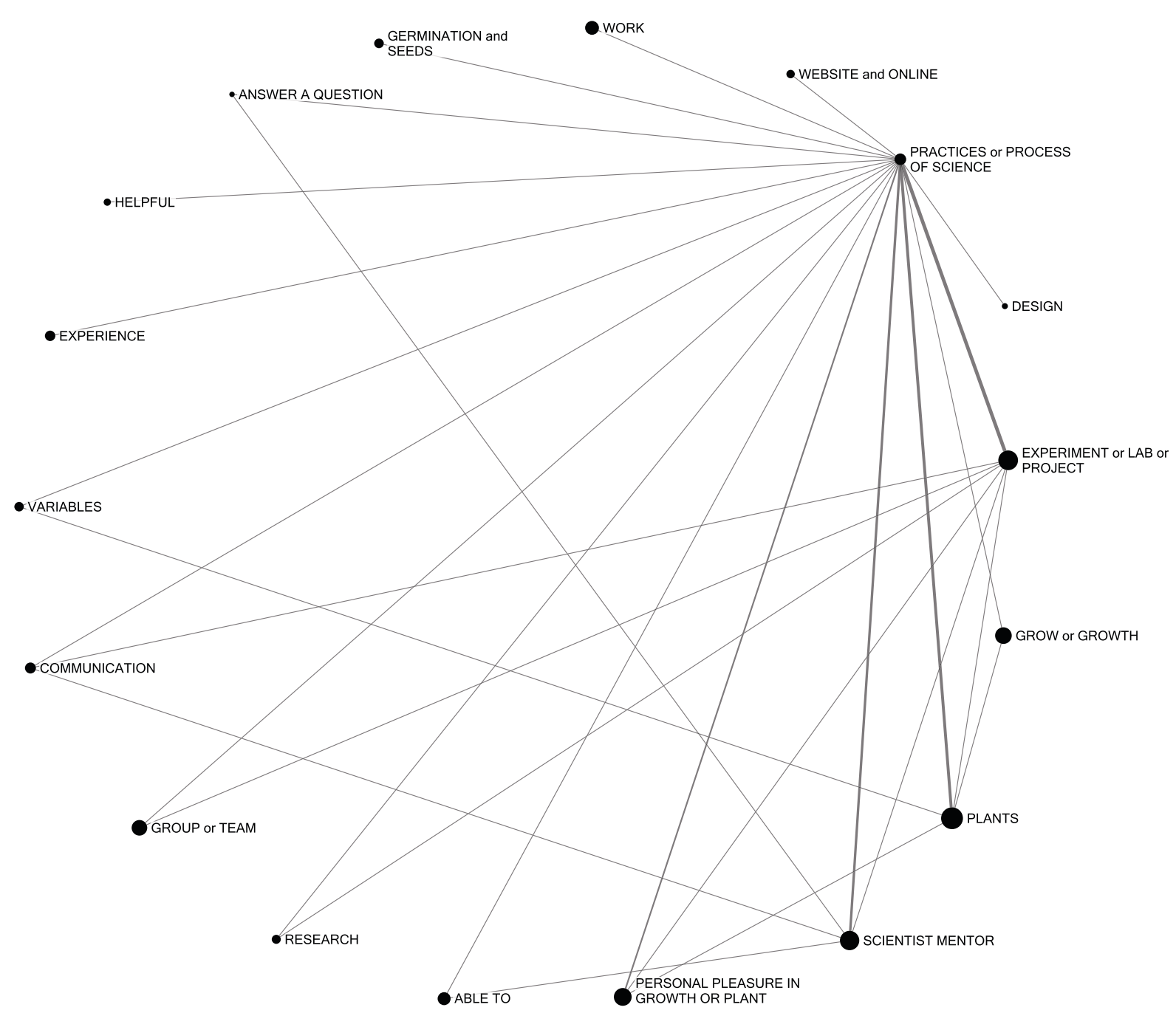

Created with NodeXL (http://nodexl.codeplex.com)

Figure 4. Lexical web illustrating connections of students' comments about liking the experiment to other favored elements. The size of the node represents the number of total respondents liking that element, and the width of the line between nodes is weighted by the number of shared responses. Items with fewer than 10 respondents are filtered out to simplify the lexical web.

learning in an undergraduate botany course (Goldberg \& Ingram 2011; Ward et al., 2014). The appreciation and caring relationships that students expressed for plants in this study invoke a sense of biophilia, which Wilson (1984) describes as the human urge to affiliate with other forms of life. To counter 'plant blindness' students need opportunities to experience the lives of plants: "this experience taught me that plants are more than what they just appear to be, they are creatures that develop in ways that are so different than mammals, humans, etc. they are a very beautiful type of species and they are very amazing to learn about."

Students' attitudes, learning, achievement, and career path are linked in close and complex ways (Osborne et al., 2003). Analyses of attitudes about science from open-ended text analysis are less common than analyses based on Likert scale responses and pose unique challenges compared to measurement of student learning (Lovelace \& Brickman, 2013). While there is a clear need for assessments that produce evidence of student content knowledge and proficiency in science practices (National Research Council, 2014), the affective domain is a powerful and under-utilized body of evidence in the development of student learning (Trujillo \& Tanner, 2014). In this analysis we began to tease out some of the indicators that students self-report as being positive to their learning experience. We see these as potentially important to the development of future instructional materials and activities and as an indicator of the effectiveness of the PlantingScience program.

These findings have implications for other projects that use technology to support more authentic science practices in science classrooms. Just doing an investigation is not sufficient for deep learning (Bell et al., 2003) and digital tools for collaboration and communication used effectively can enhance student motivation and understanding (Mistler-Jackson \& Songer, 2000). Digital learning environments generally accumulate large amounts of data rapidly. 
Without being prohibitively time consuming, the text-analysis approach allowed us to reveal broad patterns in a large set of openended data. Students participating in PlantingScience appear to give primacy to the personal science experience with the digital collaboration serving as an enhancer of the experiential learning. Placing students in an environment where they are asked to behave and think like scientists as they conduct investigations, while at the same time providing a mentor who can model scientific thinking, is a powerful combination for students to experience change in their worldview about science, scientists, and plants.

\section{Data availability}

Dataset 1. Student Responses. http://dx.doi.org/10.5256/f1000 research.6223.d44181 (Hemingway et al., 2015).

\section{Author contributions}

All authors contributed to the study design and writing of the paper. MS conducted the IBM Text Analysis. All authors have agreed to the content of the final draft of the manuscript.

\section{Competing interests}

Catrina Adams currently leads the PlantingScience program; Claire Hemingway led the program until 2013.

\section{Grant information}

Funding from the National Science Foundation (NSF DRL 0733280) supported in part the program activities of PlantingScience from 2007 to 2012. Contents of this publication are solely the responsibility of the authors and do not necessarily represent official views of the NSF. No grants were involved in supporting the study presented here.

I confirm that the funders had no role in study design, data collection and analysis, decision to publish, or preparation of the manuscript.

\section{Acknowledgements}

We thank the PlantingScience participants, steering committee, and collaborators, in particular Jane Larson and Carol Stuessy, who served as external evaluator and co-principle investigator, respectively, during the timeframe of this study.
Adams CT, Hemingway CA: What Does Online Mentorship of Secondary Science Students Look Like? BioScience. 2014; 64(11): 1042-1051. Publisher Full Text

Allen IE, Seaman J: Grade Change: Tracking Online Education in the United States. Babson Survey Research Group. 2014.

Reference Source

Arbruster P, Patel M, Johnson E, et al.: Active learning and student-centered pedagogy improve student attitudes and performance in introductory biology. CBE Life Sci Educ. 2009; 8(3): 203-213.

PubMed Abstract | Publisher Full Text | Free Full Text

Balas B, Momsen JL: Attention "blinks" differently for plants and animals. CBE Life Sci Educ. 2014; 13(3): 437-443.

PubMed Abstract | Publisher Full Text | Free Full Text

Barman CR, Stein M, McNair S, et al:: Students' Ideas about Plants and Plant Growth. Am Biol Teach. 2006; 68(2): 73-79.

Publisher Full Text

Bell RL, Blair LM, Crawford BA, et al.: Just do it? impact of a science apprenticeship program on high school students' understandings of the nature of science and scientific inquiry. J Res Sci Teach 2003; 40(5): 487-509. Publisher Full Text

Evergreen Research Group: Keeping Pace with K12 Digital Learning. 2014. Reference Source

Fancovicova J, Prokop P: Development and Initial Psychometric Assessment of the Plant Attitude Questionnaire. J Sci Educ Technol. 2010; 19(5): 415-421. Publisher Full Text

Flannery MC: Seeing Plants a Little More Clearly. Am Biol Teach. 1999; 61(4): 303-307.

Publisher Full Text

Gibson $\mathrm{H}$, Chase C: Longitudinal impact of an inquiry-based science program on middle school students' attitudes toward science. Sci Edu. 2002; 86(5): 693-705.

Publisher Full Text

Goldberg NA, Ingram KW: Improving student engagement in a lower division botany course. J Sci Scholarsh Teach Learn. 2011; 11(2): 76-90.

Reference Source

Hemingway C, Adams C, Stuhlsatz M: Dataset 1 in Digital collaborative learning: identifying what students value. F1000Research. 2015.

Data Source

Horizon Research Inc.: National Survey of Science and Mathematics Education: Status of High School Biology. 2002.

Reference Source
Horizon Research Inc.: National Survey of Science and Mathematics Education: Status of High School Biology. 2013.

Reference Source

Houseal A, Abd-El-Khalick F, Destefano L: Impact of a student-teacher-scientist partnership on students' and teachers' content knowledge, attitudes toward science, and pedagogical practices. J Res Sci Teach. 2014; 51(1): 84-115. Publisher Full Text

Kinchin IM: Investigating secondary-school girls' preferences for animals or plants: a simple "head-to-head" comparison using two unfamiliar organisms. J Biol Educ. 1999; 33(2): 95-99.

Reference Source

Krantz PD, Barrow LH: Inquiry with Seeds to Meet the Science Education Standards. Am Biol Teacher. 2006; 68(2): 92-97.

Publisher Full Text

Lindemann-Matthies P: "Lovable" mammals and "lifeless" plants": how children's interest in common local organisms can be enhanced through observations of nature. Int J Sci Educ. 2005; 27(6): 655-677.

Publisher Full Text

Link-Perez MA, Schussler EE: Elementary Botany: How Teachers in One School District Teach About Plants. Plant Sci Bull. 2013; 59(3): 99-110.

Reference Source

Lovelace M, Brickman P: Best Practices for Measuring Students' Attitudes toward Learning Science. CBE Life Sci Educ. 2013; 12(4): 606-617.

PubMed Abstract | Publisher Full Text | Free Full Text

Maltese AV, Tai RH: Pipeline persistence: Examining the association of educational experiences with earned degrees in STEM among U.S. students.

Sci Educ. 2011; 95(5): 877-907.

Publisher Full Text

Mistler-Jackson M, Songer NB: Student Motivation and Internet Technology: Are Students Empowered to Learn Science? J Res Sci Teach. 2000; 37(5):

459-479.

Publisher Full Text

National Research Council: A New Biology for the $21^{\text {st }}$ Century. The National Academies Collection: Reports funded by National Institutes of Health. The National Academies Press: Washington, DC. 2009

PubMed Abstract

National Research Council: Developing Assessments for the Next Generation Science Standards. The National Academies Press: Washington, DC. 2014 Reference Source

Osborne J, Simon S, Collins S: Attitudes towards science: A review of the literature and its implications. Int J Sci Educ. 2003; 25(9): 1049-1079. Publisher Full Text 
Randler C, Osti J, Hummel E: Decline in Interest in Biology among Elementary School Pupils during a Generation. Eurasia J Mathematics Sci Technol Educ. 2012; 8(3): 201-205. Reference Source

Stagg P, Wahlberg M, Laczik A, et al.: The Uptake of Plant Sciences in the UK: A Research Project for the Gatsby Charitable Foundation by the Centre for Education and Industry. University of Warwick. 2009. Reference Source

Summers MF, Hrabrowski FA III: Diversity. Preparing minority scientists and engineers. Science. 2006; 311(5769): 1870-1871.

PubMed Abstract | Publisher Full Tex

Taraban R, Box C, Myers R: Effects of active-learning experiences on achievement, attitudes, and behaviors in high school biology. J Res Sci Teach. 2007; 44(7): 960-979

Publisher Full Text

Trujillo G, Tanner KD: Considering the role of affect in learning: Monitoring students' self-efficacy, sense of belonging, and science identity. CBE Life Sci Educ. 2014; 13(1): 6-15.

PubMed Abstract | Publisher Full Text | Free Full Text
Uno GE: The State of Precollege Botanical Education. Am Biol Teacher. 1994; 56(5): 263-267.

Publisher Full Text

Uno GE: Botanical Literacy: What and How Should Students Learn about Plants? Am J Bot. 2009; 96(10): 1753-1759.

PubMed Abstract | Publisher Full Text

Wandersee J, Clary RM: Advances in Research Towards a Theory of Plant Blindness. 2006.

Wandersee JH, Schussler EE: Preventing Plant Blindness. Am Biol Teach. 1999; 61(2): 82-86.

Publisher Full Text

Ward JR, Clarke HD, Horton JL: Effects of a Research-Infused Botanical Curriculum on Undergraduates' Content Knowledge, STEM Competencies, and Attitudes toward Plant Sciences. CBE Life Sci Educ. 2014; 13(3):

387-396.

PubMed Abstract | Publisher Full Text | Free Full Text

Wilson EO: Biophilia. Harvard University Press Cambridge. 1984 Reference Source 


\section{Open Peer Review}

\section{Current Peer Review Status:}

\section{Version 1}

Reviewer Report 01 June 2015

https://doi.org/10.5256/f1000research.6677.r8776

(C) 2015 Scott G. This is an open access peer review report distributed under the terms of the Creative Commons Attribution License, which permits unrestricted use, distribution, and reproduction in any medium, provided the original work is properly cited.

\section{Graham Scott}

Bioscience Education Research Group, School of Biological, Biomedical and Environmental Sciences, University of Hull, Hull, UK

This paper makes an important contribution to the literature about engagement with botany in formal schooling. It presents a project that harnesses the enthusiasm of practicing scientists and the power of the internet to enable children (and their teachers) to learn about plants and practical science in an enabling environment.

The paper presents an interesting lexical analysis of the comments of a very large sample of participating children and draws out conclusions that will be of value to those individuals who care about the botanical (and wider scientific literacy) of the next generation.

I found the discussion around figure 2 and the interaction between the affective domain and cognitive domains in the context of growth particularly interesting. It complements the findings of others who have suggested that pedagogies which enhance this interaction are particularly effective and should be a focus of those of us trying to re-connect children and young people with plants and animals in the natural world.

I do have some very minor suggestions for alterations to the current version of the manuscript that the authors might like to consider:

1. Lexical analysis is not particularly common and I think therefore that it will be unfamiliar to the much of the readership of this paper. For this reason I suggest that the authors might provide a little more detail in the description of figure 1. For example, four key nodes are highlighted in the text (plants; scientist mentor; growing and experiments) but from the figure (at the resolution provided) a reader might see/infer five (plants; scientist mentor; experiment or lab project; personal pleasure in growth or plant; grow or growth; and, group or team). Perhaps a little more text to expand the methods section to explain how the four that are used were chosen (what cut off criterion was applied for example) and how these relate to the figures would be helpful.

2. I feel that the sentence "The network of comments that students made about liking most 
their mentor shows strong connections ..." is a little difficult to follow and suggest that it might be helpfully re-worded to improve the clarity of the message.

Competing Interests: No competing interests were disclosed.

\section{I confirm that I have read this submission and believe that I have an appropriate level of expertise to confirm that it is of an acceptable scientific standard.}

Reviewer Report 07 April 2015

https://doi.org/10.5256/f1000research.6677.r8133

(C) 2015 Link-Perez $\mathbf{M}$. This is an open access peer review report distributed under the terms of the Creative Commons Attribution License, which permits unrestricted use, distribution, and reproduction in any medium, provided the original work is properly cited.

\section{Melanie Link-Perez}

Department of Biology, Armstrong State University, Savannah, GA, USA

This article by Hemingway and co-authors presents the results of a lexical analysis of an openended survey question presented to secondary school students participating in the PlantingScience (www.plantingscience.org) program. The survey question probed what students most-liked about participation in the inquiry-based classroom research experience supported by online discourse with a scientist mentor.

The article is a well-written and, in my opinion, important contribution to the literature about science education in general and botanical education in particular. The major themes that emerged from the research are that students value their personal relationships both to their scientist mentor and their study organisms, and that the ability to exert some control over choice of study organism, research question, or methodology encouraged students to take ownership in their learning experience. The program's intervention of connecting student researchers with plant scientist mentors via online discourse seems particularly important given the lack of botanical training of many primary and secondary teachers and the significance of a plant mentor for stimulating lifelong interest and awareness of plants. This is an important article for increasing visibility of the PlantingScience program, but the findings have broader implications for botanical education; in particular, it provides a strong example of the value of directly exposing students to the lives of plants as an effective means of replacing plant blindness with plant appreciation and interest.

Some general comments:

Abstract is concise and clear; provides adequate context for study and presents the major conclusions.

Discussion related to Figure 4 was illuminating and suggests ways that educators can encourage students' interest in inquiry-type projects of any discipline.

The combination of the lexical webs and example student comments was an effective illustration of the major themes identified by the analysis.

Excellent selection of student quotes. 
Methods used for analysis of survey data are sound and the conclusions are justified by the data.

The paper generally is clearly written but could be improved by making some of the text more explicit. For example, consider this sentence: "For plant science, meaningful and early exposure may be critical..." As a reader, I am unclear about what the authors are implicitly stating here, and it would be better for them to be explicit about their meaning. When I read, "For plant science" in that sentence, I am left feeling that something is missing, that this thought is incomplete (What about plant science? For plant science to do what? For plant science to be considered important, valid, of interest? Critical for what?). The writing will be stronger when the connections are explicitly and completely stated.

Please elaborate on "cross-cutting concepts" in the reference to the National Research Council (2009) ("cross-cutting concepts applied in innovative solutions"), since this meaning is unclear.

I refrained from reading with an eye toward grammatical issues, but I would like to make one suggested revision: "The online platform (www.plantingscience.org) not only eliminates geographic limitations but also makes student thinking visible through its design features, enabling students, teachers and mentors to monitor thinking and learning and to provide feedback."

Thank you for the opportunity to review this excellent paper.

Competing Interests: No competing interests were disclosed.

I confirm that I have read this submission and believe that I have an appropriate level of expertise to confirm that it is of an acceptable scientific standard.

The benefits of publishing with F1000Research:

- Your article is published within days, with no editorial bias

- You can publish traditional articles, null/negative results, case reports, data notes and more

- The peer review process is transparent and collaborative

- Your article is indexed in PubMed after passing peer review

- Dedicated customer support at every stage

For pre-submission enquiries, contact research@f1000.com

F1000Research 